\title{
LEONCIO SOLORZANO ACUÑA: EL PORTAL DE PARADIGMAS PARA ORGANIZACIONES COMPETITIVAS
}

Leoncio Solorzano Acuña: The door of paradigms for competitive organizations

\author{
ERIKa Sáenz Vílchez ${ }^{1}$ \\ Universidad Nacional Mayorde San Marcos, Perú \\ (ReCibido el 17 /04/2011 - AcEPTADo el 02/06/2011)
}

El Mg. Jorge Leoncio Solórzano Acuña fue docente principal del área organizacional de la Facultad de Psicología de la Universidad Nacional Mayor de San Marcos. A lo largo de su carrera realizó diversas investigaciones en los campos del desarrollo humano y la creatividad en la cultura organizacional. Durante sus últimos años se dedicó al estudio de la prospectiva; disciplina científica, aún no muy difundida en nuestro país, que sirve como herramienta para el planeamiento de estrategias en escenarios futuros y con alto grado de incertidumbre.

En el año 2007 publicó su libro El Portal de paradigmas para organizaciones competitivas; una colección de tres tomos (Lo deseable; Lo posible; y Lo probable) en donde realiza un análisis de los cambios vertiginosos que se experimentan en la actualidad y propone alternativas ante estos nuevos desafíos que la sociedad del conocimiento y la información impone a las organizaciones, con el objetivo de lograr la evolución de la antigua organización y de esta manera contribuir a un desarrollo adecuado y saludable de las personas al interior de dicha organización.

En su primer tomo, (Lo deseable) La responsabilidad ética en los nuevos escenarios sociales, plantea las pautas a seguir para hacer frente a los nuevos y desconocidos escenarios que traen consigo las Tecnologías de Información y Comunicaciones (TIC). Este primer texto se divide en dos partes, en las que se desarrolla y articula dos temáticas de enorme valor para el éxito y perdurabilidad de las organizaciones: los paradigmas de la sociedad del conocimiento y la ética en la responsabilidad social.

En la primera parte se desarrolla un panorama de los diferentes conceptos de paradigma, al que finalmente se define como un modelo conceptual, patrón de conducta, conjunto de ideas o situaciones que facilita el cómo resolver los problemas y refleja alguna peculiaridad en el tiempo y el espacio (Solórzano, 2007); así mismo, se señala que los paradigmas ayudan a enfrentar las complejidades del medio eficientemente y son importantes para poder contener y manejar las incertidumbres que caracterizan nuestro mundo.

1 Estudiante del IX Ciclo de Psicología de la Universidad Nacional Mayor de San Marcos. E-mail: scully_2811@hotmail.com 
También se hace la distinción entre los beneficios y desventajas que implica la adopción de paradigmas, siendo la principal ventaja el permitir que el grupo de personas al interior de la organización trabaje con armonía dentro de un mismo modelo de referencia, mientras que el perjuicio más grande, es la obstrucción del futuro que genera la inercia conceptual y perceptual al negarse a los cambios.

Además se definen y presentan los factores filosófico, sociológico y científico como aquellos que determinan los paradigmas. De igual modo se dedica un capítulo al análisis de la labor del funcionario público en los últimos tiempos y se le define haciendo una distinción de su comportamiento dentro de la organización empleando los paradigmas del ayer, del mañana y del pasado mañana.

Por otro lado, se aborda el tema de la educación, da se considera como un factor decisivo para mejorar la calidad de vida y las oportunidades de desarrollo, por lo que se propone la educación con visión positiva de futuro, con la finalidad de que ésta, mediante la investigación creativa y la innovación tecnológica, pueda desarrollarse haciendo frente a las exigencias de la sociedad del conocimiento, para lo cual son necesarias políticas de Estado dirigidas a la educación, ciencia y creatividad.

Otro de los tópicos que ocupa un capítulo importante en el texto son las estrategias de responsabilidad social para el cambio; en este apartado se resalta la importancia de promover el aprendizaje y la creatividad de las personas que integran las organizaciones para lograr que dichas organizaciones puedan sobrevivir y obtengan ventajas ante los nuevos desafíos que se avecinan, asumiendo el anticiparse a los cambios y la gestión del conocimiento como formas de vida. Para lo cual se propone la potenciación del personal, promoviendo en ellos el soporte psicológico, concibiendo gerentes que sean líderes expertos en la gestión del talento humano, el manejo de equipos, y que posean un pensamiento estratégico capaz de lograr proactividad ante los cambios. Además se menciona que será importante que las organizaciones generen alianzas estratégicas entre sí con la finalidad de realizar un trabajo sinérgico que les permita el desarrollo conjunto y la supervivencia en periodos poco favorables. Así mismo uno de los requisitos para alcanzar la competitividad de la organización es que se desarrolle en ésta una cultura informática que le permita aprovechar al máximo las Tecnologías de Información y Comunicaciones.

En otro de los apartados se realiza una revisión de las competencias gerenciales desde los distintos enfoques psicológicos señalando la existencia de los modelos conductual, cognitivo, humanista y estratégico. Finalmente se proyecta cuáles serán las nuevas profesiones que en el futuro cercano tendrán una gran demanda, planteando que serán necesarios los profesionales capaces de reinventarse y adaptarse a con mayor flexibilidad y gran velocidad a las exigencias del medio.

En la segunda parte, Ética en la responsabilidad social, se realiza una revisión general del concepto de ética y se presentan diversas definiciones planteadas por especialistas. Se dedica un tópico a la comprensión de la ética, en donde se muestran los factores, afinidad, realidad y comunicación, que debidamente relacionados facilitan su comprensión y generan que la persona adopte un nuevo papel para ejercer la responsabilidad social en sus relaciones como individuo y ciudadano miembro de una comunidad. Además se aborda qué hábitos dentro de la ética deben cultivarse para lograr triunfar a nivel personal. 
Otro de los capítulos brinda su atención al papel de la familia como agente formador del estilo de vida ético, siendo ésta quien educa en el manejo de normas, además de otorgarle al individuo un soporte afectivo y valorativo. Así mismo, se resalta la importancia de la cultura ética en la educación como formador de hábitos y cuya finalidad es crear un clima de tolerancia y respeto para la formación en valores.

Por otro lado, se otorga importancia al apartado de principios éticos en la vida, en donde se destaca que para lograr la competitividad organizacional no sólo será necesario el manejo adecuado de la tecnología y la educación de calidad, sino de los principios éticos que orientan a las personas que conforman dichas organizaciones, tanto a nivel personal así como parte de la cultura organizacional, ambas direccionan las conductas hacia las buenas prácticas que adoptan.

El texto también aborda la evaluación ética como un proceso integral, permanente, participativo, autoevaluativo y prospectivo con el objetivo de detectar las dificultades presentes y proyectarse a escenarios futuros para poder emprender acciones individuales y corporativas en base a los resultados. Además se desarrolla un abordaje panorámico de las normas deontológicas y éticas profesionales, así como del código de conducta para funcionarios y el código de ético profesional comunitario.

Finalmente se concluye con el papel de la ética para el desarrollo de las organizaciones realizando una diferencia entre integrantes de una misma organización valorizando al que vive para la organización del que vive de la organización, distinguiendo claramente al hombre ético del no ético; a su vez se habla de la calidad humana en las organizaciones éticas destacando la confianza, el buen trato, la visión positiva, la generosidad, la proactividad y la sinergia como características del buen clima y del desarrollo corporativo; teniendo siempre en cuenta el papel de la ética en la toma de las decisiones organizacionales.

En su segundo tomo, (Lo probable) Estrategias para mejorar la calidad humana, el profesor Solórzano aborda tres temáticas principales, autoestima, asertividad y toma de decisiones en situaciones de incertidumbre, las que se relacionan estrechamente no solo con el crecimiento y desarrollo corporativo sino también con el de las personas al interior de la organización, demostrando así su interés no únicamente en los aspectos administrativos, sino humanos de la Psicología organizacional.

En el tópico dedicado a la Autoestima se hace una descripción minuciosa del concepto, definiéndolo desde diferentes perspectivas como un proceso, una disposición y como una acción. Así mismo se detallan las dimensiones que lo componen y los factores que influyen en su desarrollo. Además se plantean pautas para construir la autoestima y estrategias para fortalecerla; se realiza una revisión de los niveles de la autoestima y la diferenciación entre autoestima positiva y negativa.

Finalmente, se abordan los factores autoconocimiento, autoaceptación, autointerés inteligente, tolerancia a la frustración, asumir riesgos y responsabilidad emocional como los que condicionan la autoestima efectiva; los cuales favorecen la concepción de organizaciones inteligentes, caracterizadas por el buen desempeño, alta autoestima de sus integrantes expresada en la identidad y el orgullo de pertenencia a su organización, así 
como la competencia del aprender a aprender continuo para la búsqueda de la excelencia y logro de los objetivos organizacionales mediante el trabajo sinérgico.

En la segunda parte del texto se trata el tema de Asertividad como una herramienta de comunicación efectiva que conduce a relaciones y conductas saludables entre los integrantes de la organización. Se introduce al contenido a través de la revisión del concepto de comunicación, así como de las condiciones que deben cumplirse para la realización del proceso y los componentes que lo conforman. También se abordan de una manera didáctica las barreras comunicativas y los factores que obstaculizan y facilitan la comunicación. Se dedica especial atención al tópico de la comunicación en el liderazgo, en donde el autor nos brinda estrategias para lograr el éxito como líderes transformacionales que consiguen comunicarse eficazmente con su grupo.

Posteriormente, se aborda los conceptos, fundamentos y características de la asertividad, así como los tres estilos de comunicación que las personas emplean en sus relaciones interpersonales (estilo pasivo, agresivo y asertivo) en sus formas verbal y no verbal. Así mismo, el autor presenta algunas estrategias prácticas para empoderar al lector en el uso del estilo asertivo de comunicación, el cual le facilitará el manejo de sus relaciones interpersonales, así como la resolución de conflictos con el objetivo de mejorar el clima organizacional y lograr el verdadero trabajo en equipo con las personas de su entorno.

Por último, en el tercer acápite del texto, se aborda la temática de Toma de decisiones con el objetivo de desarrollar un modelo teórico que contribuya al buen desempeño organizacional frente a situaciones de incertidumbre o escaza información, enfocado desde las organizaciones que brindan servicios comunitarios. Para estos efectos se inicia con la conceptualización del proceso de toma de decisiones y la identificación de las situaciones problemas frente a las que se tendrá que optar por una alternativa de solución con el fin de realizar la mejor elección. Además se presentan los factores que influyen en el momento de la toma de decisión en la organización, tales como el manejo de información y conocimientos que tenga la persona, así como el buen criterio para optar por alguna medida; advirtiendo al lector a no confiarse únicamente en la antigüedad o la experiencia, sino describiendo el sistema complejo que conforma el proceso en mención.

Posteriormente, se presentan los modelos burocrático, racional, político, ejecutivo y creativo como diferentes modos de abordar la situación de toma de decisión, destacando al modelo creativo como el más flexible y cuya ventaja radica en su eficacia para responder acertadamente ante la incertidumbre.

El aporte que nos ofrece el profesor Solórzano en este texto finaliza con el Tomo III, (Lo posible) De la realización personal al encuentro corporativo, en donde se enfoca, desde una visión optimista de la organización centrada en la gestión humana, en tres temas que influyen necesariamente en la posibilidad de crecimiento, desarrollo y éxito de la empresa y sus integrantes. Estos temas dividen el texto en tres partes que son: las relaciones humanas saludables, el trabajo en equipo y el liderazgo en situaciones caóticas en donde se trabaja con detalle como cada una aporta en la construcción de la organización competitiva.

En la parte inicial del texto se señala que para que la organización supere y aproveche las amenazas y oportunidades de la actualidad, necesita agilidad y rapidez para cambiar 
al ritmo que la sociedad del conocimiento impone. Y para lograrlo será imperioso que las personas que conforman dicha organización tengan un espíritu innovador, creativo y emprendedor; por lo cual la organización debe ofrecerles oportunidades para su crecimiento y desarrollo que garanticen la potenciación de ese capital humano.

El autor señala también que el éxito o fracaso de la organización dependerá de cuanto conocimiento emplee y qué tan bien se maneje éste, con respecto a sus competidores; generando así una verdadera ventaja competitiva que los posicione en el mercado. Además este éxito está vinculado también al tipo de relaciones humanas que existen entre los integrantes de la empresa, dado que para evitar la mediocridad son necesarias personas con ideales y una visión interior que les permitan afrontar ciertas opiniones, paradigmas e imágenes deformadas de las personas del entorno con el cual interactúan. En otros términos, el profesor Solórzano nos señala la importancia de que en la empresa se valore la consigna, la organización avanza en la medida en que sus integrantes avanzan, por lo cual se debe promover en ellos principios como la proactividad, la visión personal, gestión de sí mismo, la escucha empática, el ganar-ganar, el trabajo sinérgico, la creatividad y el buen humor. Así mismo el texto ofrece pautas facilitadoras para mejorar las relaciones humanas en la organización, con el propósito de brindar una ayuda aplicativa práctica y didáctica para el lector.

La segunda parte de este texto se centra en la temática del trabajo en equipo al cual se considera como un factor importante de desarrollo. En este apartado se realiza una clara diferenciación entre lo que implica trabajar de manera grupal y realizar un verdadero trabajo en equipo, con el fin de promover éste último para lograr la sinergia en las organizaciones del mañana. Además se presentan los cuatro principios básicos necesarios para lograr el trabajo en equipo (físico, psicológico, de consenso y de apetencia social), así como las características que posee un equipo de trabajo, los beneficios y las barreras que existen al realizar este tipo de organización. Por otro lado se expone cómo se da la comunicación en el equipo de trabajo, destacando la existencia de buenas relaciones en las actividades que se emprenden, el manejo de los diferentes niveles de comunicación en el equipo y la asertividad como característica principal de su comunicación.

Por último, en la tercera parte del texto se desarrolla la temática de Liderazgo en situaciones de caos. Aquí se señala la importancia del buen líder, el cual debe saber conducir al equipo y manejarse dentro de situaciones conocidas a las cuales está habituado, así como en situaciones complejas que representen peligro para la organización y la consecución de sus objetivos. En este tópico se inicia con el desarrollo de los conceptos de liderazgo y las funciones del líder, diferenciando las ideas de jefe y líder según la forma como desempeña sus funciones en la organización. Además se describen los estilos de liderazgo autoritario, paternalista, democrático, anárquico y dinámico, diferenciándolos según como manejan el poder para con el grupo.

Así mismo, se propone qué debe caracterizar al líder y cómo debe ser el liderazgo para responder a la sociedad del conocimiento y generar cambios positivos en la sociedad, siendo necesario que el líder sea la persona que motive y estimule a los miembros de su equipo, así como el que maneje mejor la información y los mecanismos de comunicación para ahorrar tiempo y tener un equipo más competitivo, el líder es quien organiza y 
entrena a su equipo, además proporciona metas claras, alcanzables y posibles según las características de las personas que integran su equipo.

Finalmente se realiza una comparación entre los conceptos de liderazgo y gerencia; destacando en el liderazgo el objetivo de dirigir en base a estrategias que logren cambios que permitan alcanzar la visión de la organización, haciéndola más productiva y competitiva, mientras que la gerencia se caracteriza por la planificación de propuestas basadas en la obtención de resultados predictibles y esperados que garanticen el orden en la organización.

La nueva sociedad de los cambios vertiginosos y la producción masiva del conocimiento requiere de líderes visionarios que orienten a la organización por terrenos desconocidos, con la seguridad de lograr los objetivos de manera exitosa. Por ende estos líderes deben ser personas flexibles, creativas y capaces de dirigir al equipo por un sendero de incertidumbres con la confianza de ir avanzando en el camino, pero también con la suficiente habilidad para cambiar el rumbo cuando sea necesario.

A modo de conclusión podemos decir que el libro El Portal de paradigmas para organizaciones competitivas, es un material de lectura imprescindible para toda persona que no quiera ser abatida por los cambios del siglo XXI. La importancia de este libro radica en que en éste se exponen de manera clara y didáctica las pautas necesarias para conseguir organizaciones del futuro exitosas y responsables, en donde las personas no solo sean productivas sino que se desarrollen de manera integral, una organización en donde el personal se sienta cómodo con el clima y las relaciones entre sus compañeros y líderes, en donde la característica común sea el trabajo sinérgico, la identificación organizacional y el desarrollo personal. 